\title{
TRABALHO E IMIGRAÇÃO: EXPERIÊNCIAS A PARTIR DAS NARRATIVAS DE IMIGRANTES HAITIANOS NO OESTE DO PARANÁ
}

\author{
LABOR AND IMMIGRATION: EXPERIENCES FROM NARRATIVES \\ OF HAITIAN IMMIGRANTS IN THE WEST OF PARANÁ
}

Joselene Ieda dos Santos Lopes de Carvalho ${ }^{1}$

\begin{abstract}
RESUMO: Neste texto busco discutir a presença de imigrantes haitianos na cidade de Cascavel no oeste do Paraná e suas experiências levando em consideração aspectos geracionais, ou seja, Jean que imigrou em 2012 e que possuía 54 anos quando foi entrevistado e Mike que imigrou em 2017 e possuía 22 anos. Desta forma, busco discutir: i) como a partir do processo de imigração vivenciado de maneira semelhante e o trabalho no frigorífico incidem para experiências contraditórias acerca da expectativa de vida; ii) como a presença de imigrantes haitianos modificaram o cenário da agroindústria da carne no oeste do Paraná e destacar as pressões vividas por estes trabalhadores; iii) e por fim, como a partir da História Oral, as narrativas podem demonstrar o processo de consciência de classe destes trabalhadores que cotidianamente são relembrados da condição de imigrante em que estão sujeitos na sociedade.
\end{abstract}

PALAVRAS-CHAVE: Trabalho; Imigração; Haitianos; História Oral.

ABSTRACT: In this text I seek to discuss the presence of Haitian immigrants in the city of Cascavel in western Paraná and their experiences taking into account generational aspects, that is, Jean who immigrated in 2012 and who was 54 years old when he was interviewed and Mike who immigrated in 2017 and was 22 years old. Based on the highlighted narratives, I intend to identify the following specificities: i) how from the immigration process experienced in a similar way and the work in the slaughterhouse focus on contradictory experiences about life expectancy; ii) how the presence of Haitian immigrants changed the scenario of the meat agribusiness in western Paraná, but mainly, to highlight the pressures experienced by these workers; iii) and finally, as from Oral History, narratives can be understood as a process of class consciousness

\footnotetext{
* Pesquisa decorrente do Doutorado em História desenvolvido no Programa de Pós-Graduação em História da Universidade Estadual do Oeste do Paraná, campus de Marechal Cândido Rondon, com financiamento da Coordenação de Aperfeiçoamento de Pessoal de Nível Superior- Brasil (CAPES)- Código de Financiamento 001.
} 
of these workers who are daily reminded of the condition of immigrant in which they are subject in society.

KEYWORDS: Labor; Immigration; Haitians; Oral History.

\section{Apresentação}

Nos últimos dados disponibilizados acerca da quantidade de solicitações de refúgio no Brasil havia 11.231 refugiados legais, mas 161.057 mil solicitações de reconhecimento da condição de refugiado em trâmite, entre os principais solicitantes estavam os sírios, os venezuelanos e os haitianos. Segundo o relatório anual do Observatório de Migração (OBMIGRA, 2019) entre 2011 e 2018 foram concedidas 59.729 autorizações de residência à imigrantes pelo Conselho Nacional de Imigração (CNIg), entre eles, a maioria para os haitianos.

Expor estatisticamente estes dados têm sido tarefa fundamental para compreender o processo contemporâneo denominado pelos meios midiáticos como "crise migratória". No entanto, busco considerar neste texto que além dos números, é essencial analisarmos como os imigrantes, neste caso específico, os haitianos, lidam com as mudanças ocasionadas em suas vidas pela imigração. Sasken (2016) denominou como "expulsões" o deslocamento de pessoas de um país para outro definido pelas mais diversas situações, tais como: a falta de condições econômicas que tornam o processo de imigração como uma saída; as perseguições políticas, que em busca de ter seus direitos civis mantidos procuram novos países; a presença de países imperialistas que procuram dominar outros países considerados da periferia do capitalismo, impondo-lhes regras econômicas, sociais e culturais.

Enfim, a teoria discutida por Sasken (2016) auxilia-nos a pensar que a imigração não se trata de uma escolha individual do sujeito, ou seja, permitenos avançar as estruturas predeterminantes e compreender como nas mais variadas facetas a imigração se torna ainda que uma opção, uma forma de expulsão dessas pessoas de seus países. 
Neste texto, busco a partir de uma História comparativa entre dois imigrantes haitianos que imigraram para a cidade de Cascavel no Oeste do Paraná, elencar similaridades e distinções em suas narrativas acerca de suas trajetórias de emigração no Haiti e de trabalho no frigorífico da Coopavel, relacionado as experiências passadas, do presente de quando realizadas as entrevistas e das expectativas do futuro.

\section{Narrativas de imigração: o caso de Jean e de Mike ${ }^{2}$}

A metodologia da História Oral me permitiu conhecer Mike e Jean em 2018 quando entrevistava trabalhadores imigrantes haitianos na cidade de Cascavel. Esta cidade localizada no oeste do Paraná possui cerca de quatro mil haitianos (POLÍCIA FEDERAL, 2020) e definiu-se como rota imigratória a partir de 2012 quando empresas da região buscavam os imigrantes no acampamento do Acre para que servissem de mão de obra.

Embora não houvesse um roteiro pré-estabelecido, busquei organizar as entrevistas elencando três pontos fundamentais: i) trajetória de vida no Haiti; ii) trajetória do processo da viagem de imigração; iii) trajetória na cidade de Cascavel. A partir dessa lógica de organização da pesquisa, os próprios haitianos apresentavam suas experiências que induziam para demais temáticas que estarão presentes neste texto. Conforme salientou Thomson “(...) a evidência oral proporciona um registro essencial da história oculta da migração" (2002: 343). De modo que, a partir das narrativas, busquei reconstruir as experiências dos imigrantes e elenca-las de acordo com demais problemáticas do tempo presente.

O que pude perceber ao entrevistar Mike que em 2018 tinha 22 anos e havia chegado no Brasil fazia apenas três meses, era que suas percepções sobre a imigração e sobre as expectativas do futuro se distanciavam das experiências narradas por Jean, um dos imigrantes que entrevistei também em 2018 e que

\footnotetext{
${ }^{2}$ Os nomes dos haitianos entrevistados foram substituídos. No entanto, busquei manter a legitimidade de nomes comuns no Haiti, solicitando que me sugerissem nomes para seus pseudônimos.
} 
estava em Cascavel desde 2012. Ambos possuíam semelhanças em suas vidas, saíram do Haiti na esperança de encontrar trabalho no Brasil. Por isso, as narrativas concentravam-se nesta problemática principal: a busca, a permanência e a falta do trabalho.

Começarei apresentando Jean. Em um domingo que era o único dia de folga de Jean, me recebeu para conversarmos em sua casa. Diferentemente de outros haitianos que entrevistei e que viviam em quitinetes com cerca de cinco pessoas, Jean tinha conseguido trazer sua família e por isso, dividia a quitinete com sua esposa e seus dois filhos, mas recordou que "quando cheguei no Cascavel, cheguei a morar com doze haitiano. A gente jogava os colchões no banheiro, sala, cozinha, não tinha divisão na casa. Não era bem uma casa né? Era um espaço pra ir e dormir". Jean recordava-se deste momento na vida e em contrapartida, apesar das dificuldades da quitinete em que estava vivendo com sua família não ser a "casa dos sonhos", representava em sua narrativa um lar, aspecto do qual para a maioria dos haitianos não existia, pois, dividir a quitinete com pessoas que lhes eram estranhas era comum, o que as unia era a condição de imigrante.

A esposa de Jean cozinhava enquanto conversávamos, e em tom baixo para que ela não ouvisse Jean me contou "não suportaria ter que imigrar de novo, ainda mais para os Estados Unidos! Toda a família de Jenita está lá, é o sonho dela encontrar eles, mas não tenho mais condição". Jean não se referia apenas a condição material, mas também aos aspectos físicos e mentais de quem havia enfrentado um árduo processo de imigração até chegar ao Brasil e mesmo depois de atravessar tantas fronteiras, ainda tinha o desafio de permanecer trabalhando no frigorífico, que segundo ele "essa é a cruz que eu carrego diariamente".

Jean buscava esconder de sua esposa as calamidades sofridas até ter se estabelecido em Cascavel, pois, achava que Jenita não suportaria imaginar o quão dificultoso foi todo o processo. Ainda que, para Jenita que havia permanecido no Haiti, também tivesse sido difícil, pois, Jean não conseguiu trabalho de imediato ao chegar no Brasil, do dia em que saiu do Haiti até o dia 
em que chegou em Cascavel e começou a trabalhar no frigorífico se passaram quase seis meses. Enquanto isso, Jenita "segurava as pontas" com os dois filhos pequenos no Haiti que na época tinham dois e quatro anos. Além de buscar apoio com os familiares para dar comida para as crianças, Jenita fazia marmitas e vendia nas zonas francas no horário de expediente dos trabalhadores de indústria, tarefa da qual foi detalhada como comum para mulheres haitianas, matriarcas do lar no trabalho de Calegari (2014). Deste modo, depois de dois anos sem que Jean encontrasse sua família, com o esforço do salário que recebia no frigorífico e das marmitas que Jenita vendia nas feiras, se encontraram no aeroporto de São Paulo.

Jean contou que "eu não era o mesmo, Jenita quando me viu ficou assustada! (risos), eu tinha emagrecido mais de dez quilos e por mais que naquele dia eu estivesse com minha melhor roupa, ela dizia que eu estava diferente, acho que queria dizer feio né? (risos)". Quando Jean chegou no acampamento do Acre e durante o processo de triagem foi "escolhido" para integrar a linha de produção do frigorífico em Cascavel, parecia-lhe uma luz no fim do túnel, que logo mais se tornaria um túnel sem saída. Jenita reconhecia a diferença em Jean, afinal, ele havia mudado, durante dois anos trabalhava constantemente na linha de produção e aceitava fazer "bicos" como pedreiro nos finais de semana. O corpo que parecia padecer, era reanimado pela força de Jean em querer rever sua família e pelo medo de não conseguir trazê-los para o Brasil, aspecto comum aos demais haitianos e que também foi detalhado no trabalho de MARTINS et. al (2014) que ao conversar com estes imigrantes destacou as atrocidades em que eram submetidos em busca de auxiliar financeiramente seus familiares no Haiti até que conseguissem trazê-los para o Brasil.

Jean chegou a ser trocado mais de seis vezes entre as tarefas que realizava no frigorífico, seu horário de trabalho embora fosse estabelecido em seu contrato com a empresa, não se efetivava na prática. Jean que se considerava forte, pois, no Haiti mesmo diante das dificuldades de sobrevivência conseguia oferecer comida para sua família todos os dias, havia 
padecido no Brasil. Não havia forças para suportar o cotidiano do trabalho no frigorífico, depois de oito meses na linha de produção entre a refila do peito do frango e a evisceração, as mãos de Jean tremiam, ainda que tentasse contornar, "eu só conseguia pensar e se eu ficar assim pra sempre? Não ia arrumar trabalho em outro lugar nunca mais! A única opção que me restava era o frigorífico, isso começou me abater mais do que a distância dos meus filhos".

Em 2018, Jean ainda estava trabalhando no frigorífico, o trabalho havia o consumido drasticamente que em palavras era difícil de demonstrar, mas em sua própria narrativa Jean utilizava-se de palavras cotidianas do frigorífico como "abater" demonstrando que estava inserido na lógica de seu trabalho. No entanto, Jean não estava inerte ao processo de sua exploração, demonstrava conscientemente que não era justo o salário que recebia e a maneira como seus superiores condicionavam seu trabalho, mas na condição de imigrante, me disse que não havia muito o que fazer.

O medo permanecia na narrativa de Jean que mesmo tendo sua família próxima depois de anos de distância, não conseguia ter a garantia de que os possibilitaria uma vida digna no Brasil. Afinal, a própria vida de Jean não era digna, havia concretizado a expectativa em conseguir trabalho no Brasil e sabia que para muitos haitianos que imigraram isso era um "sonho", pois, o desemprego era uma realidade visível.

A narrativa de Jean sugeria que sua vida parecia realizar-se em círculos, todas as vezes que aparentemente as coisas iriam melhorar, Jean imediatamente era surpreendido por novos problemas. "No frigorífico eu não podia fazer mais ou menos, eu tinha que dar o meu melhor. O encarregado ficava no meu ouvido dizendo: "você é forte, você pode cortar mais do que os outros, anda haitiano, anda! Não tem medo de perder o emprego?" Jean acrescentou que "parecia que ele sabia o meu maior medo, quando falava de perder o emprego, não sei o que acontecia, vinha uma força de que eu não podia, não podia, e aí eu ficava mais rápido do que as máquinas”. De fato, os contratantes do frigorífico sabiam que os haitianos como Jean que eram buscados no acampamento do Acre, tinham o trabalho como o principal objetivo para que pudessem sobreviver e enviar 
remessas de dinheiro para os familiares que estavam no Haiti. A história de Jean não era individual, na fileira da linha de produção em que trabalhava com mais de oitenta haitianos, todos carregavam preocupações em comum de serem imigrantes e precisarem lutar pela sobrevivência diária em outro país. Tais perspectivas foram aproveitadas pelos frigoríficos no sul do Brasil, segundo Mamed (2016) eram os principais contratantes dos haitianos no acampamento do Acre.

"Depois os haitianos conversavam entre eles e dizia que no Cascavel tinha trabalho, então começou a vir muito haitiano. Isso me dava alegria por ver minha gente, mas também dava desespero porque eles (o frigorífico) usava isso contra nós", Jean era condicionado a trabalhar cada vez mais sob ameaças de que "se você não fizer, tem uma fila de haitianos ali fora querendo seu lugar" e de repente, um trabalho que Jean não aguentava mais, precisava ser mais do que suportável, era necessário que lutasse contra si mesmo para continuar no frigorífico. Essa era a principal dificuldade, pois, ele não conseguia fazer com que suas mãos parassem de tremer. A febre pela temperatura fria do frigorífico era constante, Jean sentia pesadelos e os analgésicos fornecidos pelos médicos do frigorífico pareciam não resolver sua situação. “Às vezes, no meio da noite, quando eu delirava de febre e de dor, eu ligava no celular para Jenita, não falava que estava mal, só falava que sentia saudade. Aquilo era como um combustível, mas quando ela desligava eu queria ligar de novo e contar a verdade". Jean sabia que se contasse para Jenita todo o esforço que fazia para permanecer no Brasil, sua esposa ia pedir que retornasse ao Haiti imediatamente, mas Jean se sentia o responsável pela família, queria que seus filhos pudessem estudar, ou que pelo menos tivessem mais opções na vida das quais Jean não teve.

O aumento de trabalhadores haitianos na cidade de Cascavel, traduz-se no que Marx definiu como "exército industrial de reserva". Conforme a citação abaixo:

Mas, se uma população trabalhadora excedente é produto necessário da acumulação ou desenvolvimento da riqueza com base no capitalismo, essa superpopulação torna-se, por 
sua vez, a alavanca da acumulação capitalista. Ela constitui um exército industrial de reserva disponível, que pertence ao capital de maneira tão absoluta, como se ele o tivesse criado à sua própria custa. (MARX, 1985: 200) (grifo meu)

A narrativa de Jean evidenciava tais fatos. Embora houvesse solidariedade com os demais imigrantes que recém haviam chegado ao Brasil, por outro lado, aumentava a competição acerca do trabalho. Aqueles trabalhadores imigrantes como Jean, que estavam na linha de produção e que sofriam devido a precariedade do trabalho, sentiam a necessidade de se esforçar cada dia mais e destacar motivos pelos quais a empresa deveria continuar empregando-os do que contratar trabalhadores mais jovens. Essa contradição foi elencada em diversos momentos na narrativa dos trabalhadores haitianos, como medida para tentar viabilizar o convívio com o aumento de haitianos que chegavam em Cascavel a partir de 2012, iniciou-se a divisão de quitinetes entre um número elevado de imigrantes.

Conforme pontuou Jean,

Era uma maneira da gente dividir com aqueles que não tinham trabalho para que não ficassem na rua, mas também apostava que eles ia conseguir algo um dia e retribuir, mas o mais importante era dividir pra mostrar que a gente se compadecia, então não deviam tomar nossos lugares no frigorífico. A primeira vez que um dos haitianos que trabalhava comigo contestou da gente dar um colchão pra outro que recém tinha chegado, eu conversei e expliquei a situação. Nós já estava no frigorífico fazia quase dois anos, o ritmo já não era o mesmo, não porque a gente relaxou, mas porque o corpo não aguentava mais. Os mais jovens iam encher os olhos do patrão e pegar nossas vagas. Por isso, dar um lugar na quitinete de graça sairia mais barato pra nós. (JEAN, 2018)

Jean sabia que o espaço que ocupava na linha de produção do frigorífico, poderia ser facilmente substituído. Por isso, vivia essa contradição, se de um lado Jean desejava conseguir outro trabalho e nunca mais precisar cortar frangos, em contraponto, estava sujeito à lógica capitalista que mesmo detestando seu trabalho precisava lutar para permanecer, pois, a pressão em que vivia o fazia compreender que ele precisava doar-se cada dia mais para o trabalho. "Eu passei a aceitar fazer todas as horas extras que o encarregado 
falava. Se terminava meu trabalho e via que o pessoal do empacotamento ainda tinha o que fazer, ia lá e trabalhava com eles, sem ganhar nada por isso". Mesmo que o chefe do setor em que Jean trabalhava o dissesse constantemente que podia ser substituído por trabalhadores mais jovens haitianos, ele havia incorporado esta lógica e naquele momento em que vivia, esse era o seu maior problema, ou seja, a luta para demonstrar que o trabalho deveria continuar sendo seu.

É interessante pontuar que Jean não havia feito nada de errado, não tinha notificações de atraso e mesmo quando precisava ir ao médico, fazia isso em seus horários livres. No entanto, ainda assim, compreendia que não havia garantias de que não seria substituído. Além disso, outro fator passou a ser preponderante no frigorífico, o exército industrial de reserva não atingia apenas os haitianos, mas também os trabalhadores brasileiros que buscavam ser ainda mais resistentes às normas submetidas distintas do acordado na carteira de trabalho.

Por isso, Jean se preocupava. Os brasileiros que até então conviviam harmoniosamente com os primeiros haitianos a trabalharem no frigorífico, passaram a compreendê-los como adversários, mais do que isso, "havia uns brasileiros sacanas, deixavam de fazer o trabalho deles, de cortar o frango pra aumentar na esteira de nós haitianos. Eles sabiam que nós não podia reclamar, então a gente trabalhava o dobro e ficava quieto". Se por um lado os brasileiros buscavam trapacear para que os haitianos fossem vistos como incapazes de cortar o número exatos de frangos disponibilizados na esteira, por outro lado, os haitianos se encontravam sem saída, pois, não havia com quem pudessem falar a respeito disso; não tinha sindicato que representasse os imigrantes, os encarregados entendiam as reclamações dos haitianos como falta de vontade de trabalhar e os brasileiros estavam enraivecidos com a presença massiva na linha de produção de haitianos.

A escolha do que fazer, foi apresentada por Jean, que enquanto conversava com o grupo de haitianos que moravam no mesmo grupo habitacional de quitinetes com ele, buscava amenizar a situação. Jean me 
contou que sugeriu que "vamos convidar eles pra jogar futebol no final de semana, vamos nos aproximar deles, mostrar que haitiano é gente também, que também estamos preocupados em perder nosso trabalho, que nem eles estão!”. A tática de Jean foi ignorada inicialmente por um grupo de haitianos, mas Jean persistiu e convidou alguns dos companheiros de trabalho brasileiros para jogar bola no final de semana.

Jean disse que logo que chegaram no campo disponibilizado pela empresa para a realização do jogo, houve uma aproximação entre os haitianos e os brasileiros, pois, alguns dos colegas de Jean do frigorífico haviam levado seus filhos para assistir o campeonato dos "haitianos x brasileiros" e as crianças tinham curiosidade em perguntar para os haitianos sobre suas vidas. Deste modo, Jean me contou que pela primeira vez falou de sua história para seus colegas de trabalho brasileiros e que se comoveram perguntando o porquê Jean não havia falado antes sobre suas dificuldades. Então Jean aproveitou para destacar que "haitiano não quer roubar o lugar de vocês, a gente vem desesperado tentando encontrar um lugar pra nós no mundo, pra nossa família, pro nossos filhos!". O jogo foi mais do que um momento de lazer, entre as histórias contadas, os haitianos e os brasileiros perceberam que possuíam mais semelhanças do que diferenças, inclusive acerca da maneira como eram obrigados a suportar o trabalho. Os problemas de Jean não foram todos resolvidos, mas me contou que conseguiu fazer amizades verdadeiras com os brasileiros e que mesmo depois que sua família chegou em Cascavel, de vez em quando se reuniam para jogar bola.

Já no caso de Mike a raiva que mantinha de seus companheiros de trabalho brasileiros era evidente "não fiz amizade com nenhum deles, não faço questão e nem eles! Também eu logo vou embora daqui”, ele me disse essa frase em 2018, fazia apenas alguns meses em que estava no Brasil. Em 2019 quando marquei de entrevistar outro haitiano, o reencontrei e permanecia no Brasil, morava na mesma quitinete e continuava trabalhando no frigorífico. No entanto, Mike tinha um discurso semelhante ao de 2018 quando o entrevistei pela primeira vez, "logo vou conseguir ir para os Estados Unidos, eu estou 
guardando dinheiro. O mais difícil é decidir se eu tento ir legal ou ilegal, porque de todo jeito é difícil de chegar lá, mas eu estou confiante que esse ano eu vou!". Em 2020, reencontrei Mike que ainda não havia partido para a realização do seu sonho: estar nos Estados Unidos. Sayad (1998) destacou que para os jovens argelinos que eram imigrantes na França, o que os mantinham firmes no trabalho, mesmo diante da precariedade em que viviam, era acreditar que o processo de imigração seria transitório. Percebi aspectos semelhantes ao que foi mencionado por Sayad quando conversei com ele demais imigrantes mais jovens.

Não exponho a narrativa de Mike para expressar fracasso, no campo da imigração haitiana é inconfundível o destino mais almejado: os Estados Unidos. Porém, também é sabido pelos próprios imigrantes haitianos a dificuldade em conseguir chegar até esse país, seja por meios legais, por ter que comprovar uma série de documentações das quais os haitianos não têm condições ou por meio ilegais, o agravamento das fronteiras e o estabelecimento de "muros" físicos e psíquicos na "era Trump" revelam cada dia mais tais fatores.

Mike havia passado por um processo semelhante de imigração de Jean, ambos haviam chegado no Acre e sido "escolhidos" para trabalhar no frigorífico. Mike também sentia dores, pensava em desistir do trabalho pela dificuldade de se auto reconhecer, mas o motivo que o fazia trabalhar direcionava sua vida a permanecer no frigorífico.

No meio de tantas semelhanças de Mike e Jean, havia algo que se distanciava drasticamente. Jean nos primeiros meses em que conseguiu trabalho em Cascavel, disse que sentia vontade de assim que trouxesse sua família mudar-se para os Estados Unidos, mas confessou que "foi tão difícil trazê-los, não penso em sair do Brasil. Vou ficar aqui até morrer”. Jean já não tinha expectativas sobre seu futuro, tanto que o apontamento sobre o Brasil foi justamente a sua morte, pois, sentia que estava morrendo aos poucos no trabalho que executava no frigorífico. Embora Mike também sentisse estranhamento em seu trabalho, ainda tinha expectativas acerca de seu futuro, que mencionara "longe daqui!". 
Parte da família de Mike vivia no Canadá e sua mãe com seus outros dois irmãos, viviam nos Estados Unidos. Longe de narrar uma vida tranquila, Mike me contou que também havia sido difícil o processo de imigração deles, pois, sua mãe e seus irmãos haviam ido ilegalmente para os Estados Unidos e sofriam ameaças de seus patrões norte-americanos de que se não se dedicassem e cumprissem os horários e trabalho estabelecidos, os entregariam para a polícia. Dito dessa maneira, parece contraditório o desejo de Mike de se mudar para os Estados Unidos. No entanto, após narrar a dificuldade de sua família salientou que "a diferença da vida deles pra minha é que eu sofro a mesma pressão aqui e ganho muito menos. Eu queria mandar dinheiro pra minha mãe, mas não faço isso. É ela que me manda dinheiro porque o real em dólar vira uma miséria".

Portanto, Mike sabia que a condição de imigrante não mudaria, mas financeiramente acreditava que seria melhor recompensado. $\mathrm{O}$ "sonho americano" norteava toda a sua narrativa, me mostrou em seu celular as fotografias de seus familiares em pontos turísticos nos Estados Unidos e disse que sua família perguntava sobre as praias no Brasil e então Mike me contou que "você acha que eu tenho condição de tirar férias e ir na praia? (risos) Minha família não entende o tamanho do Brasil, de como é longe e de como eu ganho pouco pra conseguir fazer isso. Se eu for para o Rio de Janeiro, sei que meu lugar vai ser na favela, por isso não quero". Mike evidenciava em sua narrativa a consciência do lugar em que o imigrante haitiano ocupa na sociedade brasileira. Além disso, relatava acerca do cotidiano da maioria das famílias trabalhadoras no Brasil em que sabem da existência de lugares bonitos e prazerosos para se passear no país, mas que nunca tiveram a oportunidade de frequentá-los.

Mike buscava desassociar sua vida de Cascavel, dizia não querer construir relações de amizades nem com os brasileiros e nem com os haitianos, como acreditava que sua estadia nessa cidade e no Brasil seria breve, concluía ser mais fácil não manter laços dos quais depois seriam difíceis de separar. 
Ele morava em uma quitinete com seis haitianos e me disse "têm vários ali que eu nem sei a história, prefiro não saber. O que me importa é gastar pouco e dividir o valor do aluguel pra sair daqui logo", Mike se mostrava apático em relação a vida dos demais imigrantes haitianos e por isso, não conseguia compreender que possuía experiências compartilhadas de forma coletiva com os demais haitianos. Por achar que vivia de modo individual, Mike carregava sobre si o fracasso de uma imigração que pensava ser provisória, mas que já estava no seu terceiro ano de distância da família.

No entanto, o sentimento demonstrado por Mike era frequentemente apresentado nas narrativas de haitianos em que entrevistei, pois, segundo Sayad (1998) é justamente esse elemento um dos mais significativos nas trajetórias dos imigrantes, ou seja, acreditar que as dificuldades passarão rapidamente e que em breve conseguirão deixar a condição de imigrante e estabelecer para si e para suas famílias uma vida digna. Deste modo, identifiquei a principal diferença entre trabalhadores haitianos que imigraram mais velhos com a faixa etária acima dos 45 anos, como Jean e de trabalhadores mais jovens como Mike com apenas 22 anos.

Jean que havia enfrentado uma trajetória de imigração ilegal como Mike, me disse que preferia morrer ao ter que passar pelas mesmas dificuldades novamente. Mike, viveu experiências muito semelhantes como o medo de atravessar as fronteiras ilegalmente, em específico na região do Peru em que os policiais conheciam a rota dos haitianos e organizavam armadilhas para que ao atravessarem fossem pegos e ameaçados de serem presos e, portanto, cedessem dinheiro em troca da passagem. No entanto, Mike tinha a expectativa de imigrar novamente de maneira ilegal para os Estados Unidos, pois, para ele, não havia possibilidade de aceitar que o futuro que almejava quando saiu do Haiti era o que vivia em Cascavel.

Diferentemente de parecer comodidade de Jean, algo evidente tornava as trajetórias geracionais vistas de maneira tão distintas. Jean era o responsável por sua família e os anos em que passou sozinho em Cascavel, acreditava que não conseguiria trazê-los, "parecia que nunca mais ia ser possível ver meus filhos 
novamente". Por isso, ainda que reconhecesse as dificuldades, foi uma grande conquista para Jean ter sua família por perto.

Mike esperava reencontrar sua família, mas buscava uma vida diferente do que apenas "sobreviver". Disse-me que queria poder arrumar um trabalho nos Estados Unidos e "sossegar", almoçar e jantar no McDonald's, comprar um tênis da moda e passear nos finais de semana. Como a família de Mike já estava nos Estados Unidos e no Canadá, Mike se sentia o excluído e mesmo que durante sua narrativa destacasse algumas das dificuldades de seus irmãos acerca do trabalho que executavam, estava vislumbrado com a possibilidade de viver o sonho americano.

Embora Jean não possuísse muitas expectativas acerca de sua vida, aliás, "meu futuro vai ser igual o presente, vou continuar me arrastando até o frigorífico. Não vejo outra saída, mas agora é diferente porque ter a Jenita e os filhos por perto me motiva mais", o que o consolava era que seu esforço pudesse de alguma maneira possibilitar uma vida melhor para seus filhos. $\mathrm{O}$ trabalho no frigorífico carregado de dor, se tornava suportável quando Jean lembrava que seus filhos pela primeira vez estavam frequentando a escola e que o sonho de sua esposa em estudar, tinha novos caminhos de possibilidades depois que iniciou os estudos na Educação de Jovens e Adultos (EJA) em uma escola no bairro onde viviam.

Mike não tinha a responsabilidade de manter sua família, pelo contrário, seus irmãos enviavam remessas de dinheiro quando podiam para que ele em breve estivesse com seus familiares. Por isso, mesmo destacando que "eu detesto o trabalho no frigorífico, todos os dias eu sofro muito em ter que vestir minha roupa pra ir trabalhar. Nada aqui faz sentido pra mim", continuava executando seu trabalho na linha de produção, pois, acreditava que essa condição seria passageira e em breve estaria realizando sua expectativa em mudar-se de país.

Além do frigorífico, Mike buscava conciliar o trabalho com um outro "bico" em que era garçom em um restaurante no horário do almoço e assim ganhava um dinheiro extra. Ademais, após o horário do expediente almoçava 
juntamente com os outros garçons o que sobrava do almoço e com isso "gasto bem menos com a alimentação. Aqui em casa nem faço parte da divisão das compras com os outros haitianos, porque eu almoço no restaurante que trabalho e tem dias que é a minha única refeição porque não dá tempo de comer, trabalhar e estudar".

Mike havia narrado como seus dias eram atribulados de tarefa em relação ao trabalho e como sua vida se reorganizara de uma maneira que desestabilizava sua própria humanidade. Ele sabia contar nos dedos as horas que tinha para dormir, pois, Mike trabalhava no turno da noite no frigorífico, chegava em casa ao amanhecer e das $11 \mathrm{~h}$ às $15 \mathrm{~h}$ trabalhava no restaurante, gastava cerca de uma hora de transporte público do lugar em que vivia até o restaurante em que trabalhava. Quando chegava em sua casa próximo das $16 \mathrm{~h}$ buscava conversar com seus familiares e descansar para que às $18 \mathrm{~h}$ começasse a se organizar para frequentar a sala de aula em uma escola que era próxima de sua casa e do frigorífico, pois, ao sair da aula às $23 \mathrm{~h}$ seguia imediatamente para o frigorífico aonde deveria estar às $00 \mathrm{~h}$.

Pra te falar a verdade é bem corrido, mas eu prefiro assim. Eu não consigo pensar muito na vida e isso é o que tem me feito continuar. Quando penso nos problemas, na minha família, começo colocar numa balança se vou conseguir ou não chegar nos Estados Unidos e isso me deixa mal com a possibilidade de nunca chegar lá. Por isso, a correria do dia a dia acaba me dando forças de imaginar que o futuro não é tão distante assim. Me sinto muito perto de conseguir ir para os Estados Unidos. Essa é a meta da minha vida, não vou parar, tem haitiano que diz que sou louco, que Trump quer ver a gente morto. Não ligo, em qualquer lugar, o imigrante, quer dizer... o haitiano, é visto de um jeito ruim, até na República Dominicana que é do lado do Haiti, eles têm raiva da gente! Então, prefiro que sintam raiva de mim nos Estados Unidos (risos). (MIKE, 2018)

Acerca deste trecho da narrativa de Mike é interessante pontuar que a imigração haitiana é concebida para a maioria das famílias como um sucesso coletivo familiar. A conquista da diáspora é apresentada como o resultado ainda que sob controvérsias, daqueles que foram fortes e conseguiram chegar em outros países e com isso, serão a principal renda dos que se mantiveram no país. 
Embora a diáspora seja um sonho recorrente entre os haitianos, a perseguição de imigrantes haitianos já teve proporções avassaladoras, por exemplo, quando o ex-presidente dominicano Rafael Trujillo em 1937 mandou perseguir e matar os imigrantes haitianos que viviam na República Dominicana.

Segundo Handerson Joseph:

O primeiro grande fluxo de (e)migração de haitianos para o exterior constituiu-se no período no qual as forças armadas americanas ocuparam Haiti (1915-1934) e República Dominicana (1912-1924) simultaneamente. Como desde o final do século XIX e o início do século XX, o crescimento das indústrias americanas de cana-de-açúcar no Caribe, particularmente em Cuba e na República Dominicana produzira uma escassez de mão de obra para trabalhar nas plantações de ambos os países, essa lacuna fora preenchida, em grande medida, pelos camponeses haitianos. (JOSEPH, 2017: 9)

Portanto, os haitianos eram vistos como aqueles que estavam "roubando" o trabalho dos dominicanos, mesmo quando aceitavam as piores tarefas e as mais difíceis condições no trabalho dos canaviais. Tal situação se assemelha ao presente narrado por Jean e Mike em que os brasileiros os entendiam como adversários, os apelidando inclusive de "papa hora extra", quando na verdade, esses haitianos aceitavam realizar os horários e as funções em que os próprios brasileiros não queriam mais. Ademais, possuíam em suas narrativas do trajeto de emigração a função de uma diáspora que desse certo de qualquer maneira, ainda que para isso fosse preciso desumanizar seus corpos.

\section{Considerações finais}

Jean e Mike são apenas alguns dos trabalhadores imigrantes haitianos que tive contato, e que fazem parte de uma pesquisa mais ampla que discuto em minha tese de doutorado, mas de maneira geral a experiência da classe trabalhadora, e em específico, a que trabalha na linha de produção de frigoríficos acentua a dificuldade de não padecer perante um trabalho que lhes causa estranhamento. É importante mencionar que embora a imigração faça parte da vida desses trabalhadores, é equivocado pensar que saem do Haiti 
procurando uma vida conforme foi narrada por Jean, acerca da naturalização sobre a exploração do trabalho.

Jean possuía um ofício no Haiti, havia aprendido com seu pai e seu avô a ser marceneiro. Durante parte da sua vida, trabalhava com sua família e esse era o sustento da casa. Quando decidiu imigrar, acreditava que melhoraria não apenas sua condição, mas a de seus familiares que haviam permanecido no Haiti. Jean se decepcionou quando percebeu como seria difícil ter sua esposa e seus filhos novamente por perto, quando realizou a grande conquista de tê-los em Cascavel, entendeu que não deveria tirar seu pai do Haiti para que chegasse no Brasil e tivesse que viver como Jean vivia, pois, lhe causava espanto precisar de um trabalho que não precisava dele, aliás, consumia ao máximo sua condição humana, mas que poderia substitui-lo facilmente.

Mike é de uma geração distinta da em que nasceu Jean. Mike trabalhou na linha de costura em uma zona franca no Haiti durante três anos. Embora me contou que não sabia costurar e que o dia a dia na fábrica o surpreendeu, pois, havia aprendido algo novo, Mike não havia adquirido um ofício. Ele realizava pequenos cortes que em seguida eram efetivados por demais mulheres em máquinas e assim, funcionava a linha de produção no Haiti. Por isso, Mike não tinha um passado acerca de um trabalho que havia exigido de si além de força física, pois, as atividades eram repetitivas e ele mesmo contou que "comecei era ainda criança na fábrica", ou seja, se uma criança era capaz de realizar os movimentos, Mike entendia que o valor de seu trabalho era apenas o salário que recebia.

Dessa forma, os conflitos vividos durante o processo de imigração e o resultado deles no momento em que estes trabalhadores haitianos interpretam suas vidas condicionam às três temporalidades: passado, presente e futuro.

Assim, a imigração é entendida por cada um de acordo com sua experiência particular, mas quando reunimos as histórias contadas, as dificuldades enfrentadas e a luta por uma vida mais digna, torna-se evidente que podemos afirmar que estes imigrantes fazem parte da classe trabalhadora no Brasil, pois, mais do que distinções com os demais trabalhadores, possuem 
diversas experiências em comum, sendo a mais significativa delas a luta por sobreviver em uma sociedade que insiste em fazê-los padecer todos os dias.

\section{Referências}

CALEGARI, Jorge O. Codemò: escravos sem grilhões: vida operária ao redor da zona franca CODEVI em Ouanaminthe. Dissertação no Instituto de Filosofia e Ciências Humanas, Universidade Estadual de Campinas, 2014.

JOSEPH, Handerson. A historicidade da (e)migração internacional haitiana. O Brasil como novo espaço imigratório. Périplos: Revista de Investigación sobre Migraciones. Brasília, vol. 1, $\mathrm{n}^{\mathrm{o}}$ 1, pp. 7-26, 2017. Disponível em: https://periodicos.unb.br/index.php/obmigra_periplos/article/view/5866. Acesso em: 30 jun. 2020.

MARTINS, José Renato; SOUZA, Maria Adélia; ARAUJO, Danielle Michelle; ZOMICHANI JUNIOR, James. Diáspora haitiana: da utopia à realidade. Foz do Iguaçu- PR: Gráfica Grapel, 2014.

MARX, Karl. O capital: crítica da economia política. São Paulo: Nova Cultural, 1985.

MAMED, Letícia. Haitianos na Amazônia: a morfologia da imigração haitiana pelo Acre e o horizonte de inserção precarizada no Brasil. Ruris. São Paulo, vol. 10, $\mathrm{n}^{\mathrm{o}}$ 10, pp.73-111, 2016. Disponível em: https://www.ifch.unicamp.br/ojs/index.php/ruris/article/view/2636. Acesso em: 30 jun. 2020.

SASKEN, Saskia. Expulsões: brutalidade e complexidade na economia global. São Paulo: Paz e Terra, 2016.

SAYAD, Abdelmalek. A Imigração ou os Paradoxos da Alteridade. São Paulo: Editora da Universidade de São Paulo, 1998.

THOMSON, Alistair. Histórias (co)movedoras: história oral e estudos de migração. Revista Brasileira de História. São Paulo, vol. 22, nº 44, pp. 341364, 2002. Disponível em: https://www.scielo.br/pdf/rbh/v22n44/14003.pdf. Acesso em: 15 jun. 2020.

Recebido em: 31 de maio de 2020 Aceito em: 30 de julho de 2020 